\title{
Systemic Absorption of Gentamicin Irrigation in Joint Replacement Surgery: A cause of concern
}

\author{
KH Lee, MS (Orth), ABY Ng*, FRCS (Tr \& Orth), TB Tan**, MS (Orth), K Mossinac***, FRCS(Glas), \\ BC Se To, FRCS (Ed) \\ Dept of Orthopaedic \& Tramatology, Penang Hospital, Georgetown, Malaysia \\ * Dept of Orthopaedics, Wrightington Hospital, Wigan, United Kingdom \\ ** Dept of Orthopaedics, Metro Specialist Hospital, Sungai Petani, Malaysia \\ ${ }^{* \star *}$ Faculty of Surgery, Penang Medical College, Georgetown, Malaysia
}

\begin{abstract}
Gentamicin, whether administered either intravenously, incorporated into bone cement or for local intra-operative irrigation, is a commonly used antibiotic in orthopaedic practice. The former two have been well studied, however the literature on the therapeutic efficacy and safety of gentamicin irrigation is sparse. The objective of this study was to assess systemic absorption of gentamicin irrigation in joint replacement surgery. This was a non-randomised, prospective study. Ninety-eight patients (group A) who underwent total joint replacement and 40 patients (group B) who underwent hemi-arthroplasty were treated intraoperatively with gentamicin irrigation. Serum gentamicin levels were assayed at 4 hours and 24 hours post-surgery. Sixteen of 98 patients in group A (16\%) and 12 out of 40 patients in group B (30\%) were found to have serum gentamicin level above $2 \mathrm{mcg} / \mathrm{ml}$ at 4 hours post-surgery. We conclude that intra-articular gentamicin irrigation is systemically absorbed at substantial levels.
\end{abstract}

Key Words:

Joint Replacement, Gentamicin irrigation, Gentamicin Absorption

\section{INTRODUCTION}

Infection following joint replacement surgery is a devastating complication for the patient and is costly for patients, surgeons, hospitals and third party payers ${ }^{1}$. The incidence rate of postoperative infection in this population is one to two percent as reported in the literature ${ }^{2-6}$. Contemporary methods of prophylaxis for infection such as perioperative antibiotics, laminar air flow surgical suites and body-exhaust systems have shown to reduce postoperative sepsis ${ }^{3,7}$. The rate is further reduced if antibiotics and laminar flow suites are used together ${ }^{8,9}$. The introduction of antibiotic cement in cemented joint arthroplasty surgery has also had a beneficial in the reduction of deep sepsis following joint replacement surgery ${ }^{10}$. Attempts to further reduce the incidence of post-operative wound sepsis also have included topical antibiotic irrigation during prosthesis implantation ${ }^{11,12}$, however the practice remains controversial due to reports of adverse effects and lack of clinical efficacy documentation in the literature ${ }^{13-15}$. The primary objective of this study was to determine whether systemic absorption occurs after topical gentamicin irrigation during joint replacement surgery.

\section{MATERIALS AND METHODS}

Patients who underwent total knee replacement, total hip replacement and hemi-arthroplasty of the hips and shoulders at Hospital Pulau Pinang, Malaysia from July 2003 to July 2004 were included in this study. The same surgeon operated on all patients. Patients with renal impairment, on intravenous gentamicin therapy and patients who had intraoperative complications such as bleeding, prolonged surgery and iatrogenic fractures were excluded from this study. Patients received intravenous Cefuroxime $1.5 \mathrm{gm}$ prophylactically prior to surgery and $750 \mathrm{mg}$ every 8 hours post-operatively for 2 doses. Intra-operatively, four ampoules of gentamicin (total, $320 \mathrm{mg}$ ) were used. Two ampoules of gentamicin $(180 \mathrm{mg}$ ) diluted with $20 \mathrm{mls}$ of normal saline, were used to irrigate the wound prior to prosthesis implantation and another two ampoules $(180 \mathrm{mg})$ diluted with $20 \mathrm{mls}$ of normal saline were used for irrigation prior to wound closure. Non-antibiotic impregnated cement was used in this study. Pulsatile lavage was not used in this study. A single drainage tube was inserted into the joint before wound closure.

Venous blood was drawn for serum gentamicin levels at 4 and 24 hours post-operatively and renal function was monitored as well.. All patients were followed for any signs and symptoms of post-operative wound infection or renal impairment. Superficial wound infection was recorded if the wound was inflamed with erythema and induration, but did not requiring any further surgical procedures. Any infection 
extending beyond the deep fascia that needed surgical exploration, drainage or implant revision was classified as deep infection. Statistical analysis was performed using SPSS statistical software (version 8.0 for Windows SPSS Inc, Chicago, Illinois). Statistical significance was established at the $\mathrm{p}<0.001$ levels

This study was terminated in July 2004 when the authors noted that results revealed significant systemic absorption of gentamicin irrigation. The practice of antibiotic irrigation during orthopaedic surgery was discontinued in our institution at that time.

\section{RESULTS}

A total of one hundred and eighty patients had joint replacement surgery during the time period in which this study was conducted. Forty-two patients were excluded due to failure to fulfil the inclusion criteria or incomplete clinical data. Out of the remaining one hundred and thirty-eight patients, ninety-eight patients had total joint replacement (group A) and forty had hemi-arthroplasty (group B).

In group A, there were 23 patients with total hip replacements and 75 total knee replacements. Justification for the surgical procedure included: osteoarthritis, 79; rheumatoid arthritis, 3; proximal femur fracture, 8; and avascular necrosis of the femur head, 4 . The mean age for group A was 63.5 years (ranged 28-80y). Forty-seven underwent surgery on the left side and 51 on the right. In group B, there were 40 patients with hemi-arthroplasties of the hips and shoulders (Austin-Moore hip arthroplasty, 2; bipolar hip arthroplasty, 2; and hemi- shoulder arthroplasty, 3). The mean age for group B was 71.3 years (ranged 37-87y) (Fig. 1). Twenty-three patients underwent procedures on the left side and 17 on the right. Patients in group B were statistically significantly older than those in group A and the difference was statistically significant (Student $\mathrm{T}$ test: $\mathrm{p}<$ 0.001). However, there was no significant difference in term of medical comorbidities (Chi-square test, $\mathrm{p}=0.607$ ). A majority $(96.4 \%)$ of the patients were female.

In group A, the mean serum gentamicin level at 4 hours postsurgery was $1.65 \mathrm{mcg} / \mathrm{ml}$ (range, 0.00 to $16.06 \mathrm{mcg} / \mathrm{ml}$ ). Sixteen out of ninety-eight patients (16\%) showed serum gentamicin levels above $2.00 \mathrm{mcg} / \mathrm{ml}$, and in three patients the level was more than $10.00 \mathrm{mcg} / \mathrm{ml}$ (Table I). At 24 hours post-surgery, the mean serum gentamicin was $0.47 \mathrm{mcg} / \mathrm{ml}$ (range, 0.00 to $6.32 \mathrm{mcg} / \mathrm{ml}$ ), and five patients $(5.1 \%)$ still had serum gentamicin level above $2 \mathrm{mcg} / \mathrm{ml}$ at this stage (Table II).

In group $\mathrm{B}$, the mean serum gentamicin level was $4.06 \mathrm{mcg} / \mathrm{ml}$ (ranged from 0.13 to $39.57 \mathrm{mcg} / \mathrm{ml}$ ) after 4 hours post-surgery, and twelve out of forty patients $(30 \%)$ had serum gentamicin levels above $2.00 \mathrm{mcg} / \mathrm{ml}$. Four patients had levels above $10.00 \mathrm{mcg} / \mathrm{ml}$ (Table I). At 24 hours postsurgery, the mean serum gentamicin level was $0.48 \mathrm{mcg} / \mathrm{ml}$ (range, 0.00 to $4.42 \mathrm{mcg} / \mathrm{ml}$ ) and only one patient had a level above $2.00 \mathrm{mcg} / \mathrm{ml}$ (Table II). There was no significant difference between serum gentamicin levels found in group A and group B at $4(\mathrm{p}=0.114)$ and 24 hours $(\mathrm{p}=0.826)$ postoperation (Table III).

All patients were followed up at one month, three months, six months and subsequently one-year intervals. None of the patients in either group developed systemic complications that can be associated with the use of gentamicin. All renal functions remain normal and there were no signs and symptoms of nephrotoxicity and ototoxicity.

In group A, six patients (6.1\%) developed a superficial wound infection. All of these had a total knee replacement. Four out of these six patients have pre-existing diabetes mellitus, and their infection resolved following treatment with intravenous antibiotics. None required further surgery or revision for infection. No infection was noted in group B.

\section{DISCUSSION}

Infection remains a devastating complication of total joint replacement surgery, and represents a significant burden for both patient and surgeon, but despite exhaustive prophylactic measures, infection rates still remain at $1-2 \%{ }^{3-6}$. Contemporary methods such as peri-operative prophylactic antibiotics, laminar airflow operating suites and bodyexhaust systems have reduced the incidence of deep sepsis after total joint replacement surgeries and the use of antibiotic bone cement in cemented total joint replacement is effective in combination with other prophylactic

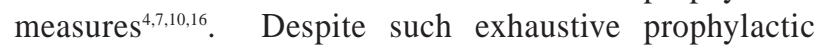
measures, intraoperative contamination is still possible ${ }^{2}$, thus leading to the recommendation for use of diluted topical antibiotics for irrigation to reduce intra- and post-operative wound infection has been recommended ${ }^{11,12,29-31}$. There have however been reports of anaphylactic reactions following the use of Bacitracin irrigation ${ }^{13,17}$, and systemic absorption is also a concern ${ }^{182}$. This raises the issue of and concern about the safety of using diluted topical antibiotics irrigation in surgical wounds. Weinstein et al. demonstrated that systemic absorption of neomycin sulphate occurred in patients who underwent total hip replacement with intra-operative neomycin wound irrigation, thus increasing the risk of nephrotoxicity and ototoxicity ${ }^{21}$.

Gentamicin belongs to the aminoglycoside class of antibiotic. It covers a broad spectrum of organism including certain type of gram positive and most of the gram- negative bacteria. Even when its association with ototoxicity and nephrotoxicity is well established, it remains one of the commonest antibiotics used both intravenously or topically due to its good coverage, less resistance and low cost. 
Table I: 4 hours post-operation plasma gentamicin level

\begin{tabular}{|lcc|}
\hline Blood gentamicin level $(\boldsymbol{\mu g} / \mathbf{m l})$ & Group A & Group B \\
\hline $0.00----2.00$ & 82 & 28 \\
$2.01----4.00$ & 8 & 3 \\
$4.01----6.00$ & 2 & 2 \\
$6.01----8.00$ & 2 & 0 \\
$8.01----10.00$ & 1 & 3 \\
$10.01---20.00$ & 3 & 1 \\
$20.01---30.00$ & 0 & 2 \\
$30.01---40.00$ & 0 & 1 \\
Total & 98 & 40 \\
\hline
\end{tabular}

Table Il: 24 hours post-operation serum gentamicin level

\begin{tabular}{|lcc|}
\hline Serum gentamicin level $(\boldsymbol{\mu g} / \mathbf{m l})$ & Group A & Group B \\
\hline $0.00-2.00$ & 93 & 39 \\
$2.01-4.00$ & 1 & 0 \\
$4.01-6.00$ & 2 & 1 \\
$6.01-8.00$ & 2 & 0 \\
$8.01-10.00$ & 0 & 0 \\
$10.01-20.00$ & 0 & 0 \\
$20.01-30.00$ & 0 & 0 \\
$30.01-40.00$ & 0 & 0 \\
Total & 98 & 40 \\
\end{tabular}

Table III: Serum gentamicin at 4 and 24 hours

\begin{tabular}{|clcc|}
\hline & & 4 hours post-surgery & 24 hours post-surgery \\
\hline Group A & $>2 \mathrm{mcg} / \mathrm{ml}$ & $82(16 \%)$ & $5(5.1 \%)$ \\
& $<2 \mathrm{mcg} / \mathrm{ml}$ & $16(84 \%)$ & $93(94.9 \%)$ \\
& Mean & $1.65 \mathrm{mcg} / \mathrm{ml}$ & $0.47 \mathrm{mcg} / \mathrm{ml}$ \\
& Median & $6.860 \mathrm{mcg} / \mathrm{ml}$ & $0.210 \mathrm{mcg} / \mathrm{ml}$ \\
Group B & $>2 \mathrm{mcg} / \mathrm{ml}$ & $12(30 \%)$ & $1(2.5 \%)$ \\
& $<2 \mathrm{mcg} / \mathrm{ml}$ & $28(70 \%)$ & $39(97.5)$ \\
& Mean & $4.06 \mathrm{mcg} / \mathrm{ml}$ & $0.48 \mathrm{mcg} / \mathrm{ml}$ \\
& Median & $3.890 \mathrm{mcg} / \mathrm{ml}$ & $0.265 \mathrm{mcg} / \mathrm{ml}$ \\
\hline
\end{tabular}

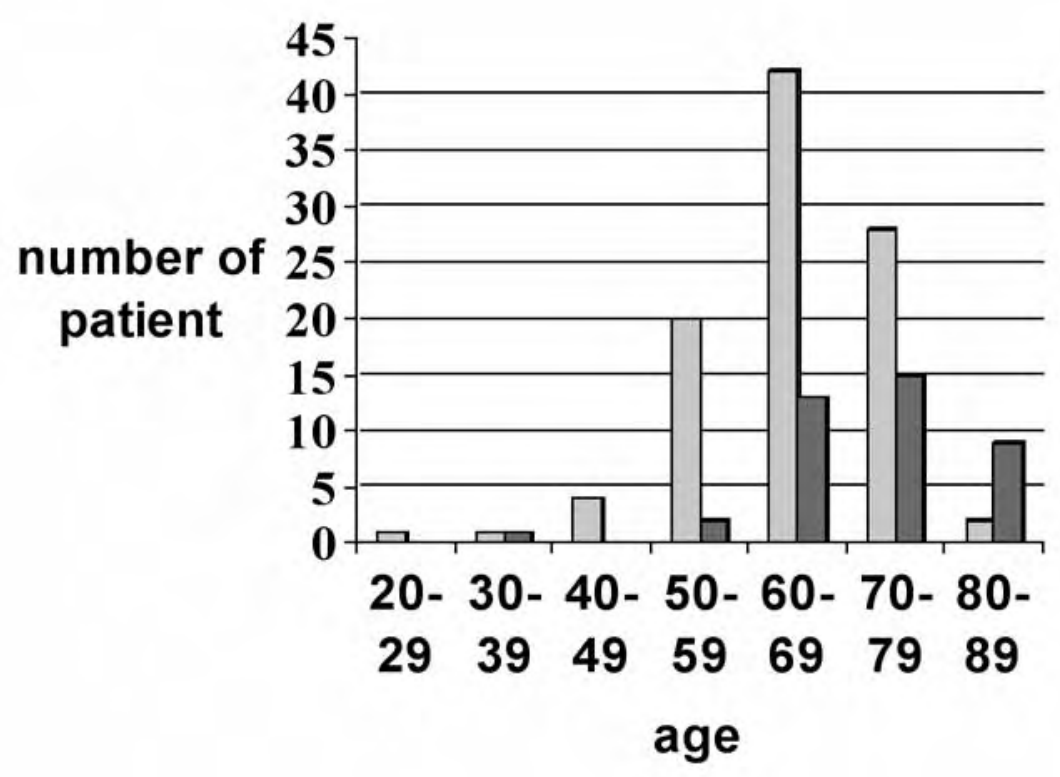

\section{Total joint replacement Hemiarthroplasty}

Fig. 1: Age distribution of patients

Gentamicin also has been widely used for irrigation in practice of medicine. Examples are bladder irrigation, nasal irrigation, conjunctival irrigation in cataract surgery and mediastinal irrigation in cardiac surgery ${ }^{19,22}$. As Gentamicin impregnated bone cement and beads had been well studied and widely accepted in orthopaedic practice, the use of gentamicin as irrigant in joint replacement surgery has been popular but poorly understood. We were not able to find published data on the systemic absorption and beneficial effect of gentamicin irrigation in different types of joint replacement surgery.
There is very narrow therapeutic index for gentamicin ${ }^{25-28}$. In clinical practice, when intravenous gentamicin is prescribed to a patient, the serum gentamicin level should be maintained below $2 \mathrm{mcg} / \mathrm{ml}$. Serum level above $12 \mathrm{mcg} / \mathrm{ml}$ shortly after delivery (post-dosage) should also be avoided. High peak and/or trough serum concentrations of gentamicin increase the risk of nephrotoxicity and ototoxicity ${ }^{25-27}$. Acute renal failure after use of gentamicin-impregnated beads and block spacer has been reported ${ }^{22}$. The possibility of systemic absorption is of most concern when gentamicin is used as an irrigation solution in joint replacement surgery because such procedures are mostly performed on the elderly; this 
population is more vulnerable to such toxicity because pharmacokinetic variability is known to be more prevalent in the aged ${ }^{23,27,28}$. There is also question of the efficacy of gentamicin irrigation in term of infection control in joint replacement surgery. The present study includes group A (total joint replacements) and group B (hemi-arthroplasty). Both groups shown significant increased in serum gentamicin level beyond $2 \mathrm{mcg} / \mathrm{ml}(16 \%$ and $30 \%)$ at 4 hours after procedure.

Results reported in the current manuscript also raise the concern of potential nephrotoxicity and ototoxicity, since even at 24 hours following surgery, Group B had more patients with high serum gentamicin levels (although the number is not statistically significant). The absolute gentamicin levels were also much higher in group B patients. One possible explanation for this difference between groups is that the mean age of patients was higher in group B. As elderly patients have substantial pharmacokinetic variability and unpredictable renal clearance as compared to more youthful populations, they maybe more susceptible to the effect of the drug ${ }^{23}$. There was however no clinical or biochemical evidence of renal impairment. This was not unexpected as the duration of exposure to the gentamicin in these patients was relatively short.

The incidence of superficial infection was $6.1 \%$ in group A, meaning that the practice of topical gentamicin irrigation into the joint did not reduce infection rate in total joint replacement procedures, and thus raising the concern that the institution would be promoting the promotion of unnecessary antibiotic resistance if the irrigation practice were to continue. Likewise, Anglen has shown that antibiotic irrigation demonstrated no improvement in outcome in prospective studies ${ }^{24}$. There are at least three reasons not to use antibiotics if they are not effective: unnecessary cost; rare but serious risk of toxicity; and promotion of antibiotic resistance ${ }^{15}$. The lack of a prospective, double blinded and randomised trial design was a weakness of the study, and without a control group, we were unable to directly compare the infection rate of the surgeries. There were also questions of other variables involved in joint replacement surgeries, as there were different surface areas and varying blood supplies for the different types of surgery studied herein. Nevertheless, the study demonstrated that substantial systemic absorption occurred when topical gentamicin irrigation was used for total knee replacement, total hip replacement and hemi-arthroplasty of the hips and shoulders at our institution.

\section{CONCLUSION}

This study demonstrated that substantial systemic absorption of gentamicin occurred in patients undergoing joint replacement surgeries in which diluted gentamicin irrigating solution is used. Although gentamicin toxicity usually occurs after repeated high dose exposure, the risk must be taken into consideration especially since we were not able to demonstrate any beneficial effect in the reduction of wound infection.

\section{ACKNOWLEDGEMENT}

The authors would like to thank the Therapeutic Drug Monitoring (TDM) service in Penang Hospital for their collaboration in the measurement of gentamicin concentrations for this study. A special thank to Dr Terence Tay for helping us to prepare the Microsoft Excel file containing all the patient's data and information. The authors did not receive any grants or outside funding in support of this research or preparation of this manuscript. They did not receive payments or other benefits or a commitment or agreement to provide such benefits from a commercial entity. No commercial entity paid or directed, or agreed to pay or directed, any benefits to any research fund, foundation, educational institution, or other charitable or non-profit organization with which the authors are affiliated or associated. 


\section{REFERENCES}

1. Bozic KJ, Ries MD. The impact of infection after total hip arthroplasty on hospital and surgeon resource utilization. J Bone Joint Surg (Am) 2005; 87(8): 1746-51.

2. Byrne AM, Morris S, McCarthy T, Quinlan W, O'Byrne JM. Outcome following deep wound contamination in cemented arthroplasty. Int orthop 2007; 31(1): 27-31.

3. Salvati EA, Robinson RP, Zeno SM, Koslin BL, Brause BD, Wilson PD Jr. Infection rates after 3175 total hip and total knee replacements performed with and without a horizontal unidirectional filtered air-flow system. J Bone Joint Surg (Am) 1982; 64(4): 525-35.

4. Lynch M, Esser MP, Shelley P m Wroblewski BM. Deep infection in Charnley low-friction arthroplasty. J Bone Joint Surg (Br) 1987; 69(3): 355-59.

5. Fitzgerald RH, Nolan DR, Ilstrup DM, Van Scoy RE. Deep wound sepsis following total hip arthroplasty. J Bone Joint Surg (Am) 1977; 59(7): 847-55.

6. Segawa H, Tsukayama DT, Kyle RF, Becker DA, Gustilo RB. Infection after total knee arthroplasty. J Bone Joint Surg (Am) 1999; 81(10): 1434-44.

7. Schutzer SF, Harris WH. Deep-wound infection after total hip replacement under contemporary aseptic conditions. J Bone Joint Surg (Am) 1988; 70(5): 724-7.

8. Lidwell OM, Lowbury EJ, Whyte, Blowers R, Stanley SJ, Lowe D. Infection and sepsis after operations for total hip or knee joint replacement: influence of ultraclean air, prophylactic antibiotics and other factors. J Hyg (Lond) 1984; 93(3): 505-29.

9. Lidwell OM, Elson RA, Lowbury EJ, Whyte W, Blowers R, Stanley SJ, Lowe D. Ultraclean air and antibiotics for prevention of postoperative infection. A multicenter study of 8,052 joint replacement operations. Acta Orthop Scand 1987; 58(1): 4-13.

10. Block JE, Stubbs HA. Reducing the risk of deep wound infection in primary joint arthroplasty with antibiotic bone cement. Orthopedics 2005; 28(11): 1334-45.

11. Benjamin JB, Voiz RG. Efficacy pf a topical antibiotic irrigant in decreasing or eliminating bacterial contamination in surgical wounds. Clin Orthop Relat. Res 1984 Apr; (184): 114-7.

12. Dirschl DR, Wilson FC. Topical antibiotic irrigation in the prophylaxis of operative wound infections in orthopaedic surgery. Orthop Clin North Am 1991 Jul; 22(3): 419-26.

13. Antevil JL, Muldoon MP, Battaglia M, Green R. Intraoperative anaphylactic shock associated with bacitracin irrigation during revision total knee arthroplasty. A case report. J Bone Joint Surg (Am) 85: 339-342, 2003.

14. Whatley WS, Chandra RK, MacDonald CB. Systemic absorption of gentamicin nasal irrigations. Am J Rhinol 2006 May-Jun; 20(3): 251-4.

15. Anglen JO. Wound irrigation in musculoskeletal injury. J Am Acad Orthop Surg 2001 Jul-Aug; 9 (4): 219-26.

16. Lidwell OM, Lowbury EJ, Whyte W, Blowers R, Stanley SJ, Lowe D. Effect of ultraclean air in operating rooms on deep sepsis in the joint after total hip or knee replacement: a randomised study. Br Med J (Clin Res ed) 1982: 285(6334): 10-4.

17. Blas M, Briesacher KS, Lobato EB. Bacitracin irrigation: A cause of anaphylaxis in operation room. Case report. Anesth Analg 2000; 91: 1027-8.

18. Trope GE, Lawrence JR, Hind VM, Everden A. Systemic absorption of topical and subconjunctival gentamicin. Br J Ophthalmol 1979 Oct; 63 (10): 692-3.

19. Kopel ME, Riemersma L, Finlayson DC, Tobia V, Jones EL, Hall RI, Mullins R, Lampasona V. Gentamicin solution for mediastinal irrigation: systemic absorption, bactericidal activity, and toxicity. Ann Rhorac Surg 1989 Aug; 48 (2): 228-31.

20. Defoor W, Ferguson D, Mashni S, Reeves D, Minevich E, Reddy P, Sheldon C. Safety of gentamicin bladder irrigations in complex urological cases. J Urol 2006; 175(5): 1861-4.

21. Weinstein AJ, McHenry MC, Gavan TL. Systemic absorption of neomycin irrigating solution. JAMA 1977; 238 (2): $152-3$

22. Van Raaij TM, Visser LE, Vulto AG, Vulto AG, Verhaar JA. Acute renal failure after local gentamicin treatment in an infected total knee arthroplasty. J Arthroplasty 2002; 17(7): 948-50. 
23. Triggs E, Charles B. Pharmacokinetics and therapeutic drug monitoring of gentamicin in the elderly. Clin Pharmacokinet 1990; 37(4): 331-41.

24. Anglen JO. Comparison of soap and antibiotic solutions for irrigation of lower-limb open fracture wounds. A prospective, randomized study. J Bone Joint Surg (Am) 2005; 87: 1415-1422.

25. Ismail R, Sarriff A, Abdul Rahman AF. Therapeutic drug monitoring for gentamicin in Hospital Universiti Sains Malaysia. Med J Malaysia 1990; 45: 57-64.

26. Hussin Z, Lim VK. Monitoring of serum gentamicin level in a general hospital. Med J Malaysia 1982; 37:104-7.

27. Drug Reference Encyclopaedia. Available from URL: http://www.theodora.com/drugs/garamycin_injectable_schering.html [Accessed 2008 Sept 25]

28. Gentamicin official FDA information, side effects and uses. Available from URL: http://www.drugs.com/pro/gentamicininjection [Accessed 2008 month day]

29. Bourgeois FJ, Pinkerton,JA, Andersen W and Thiagarajah S. Antibiotic irrigation prophylaxis in the high-risk cesarean section patient. Am. J. Obstet. Gynecol. 153: 197, 1985

30. Lord JW, LaRaja RD, Daliana M and Gordon MT. Prophylactic antibiotic wound irrigation in gastric, biliary, and colonic surgery. Am. J. Surg. 145: 209, 19

31. Nelson KJ, Gallup DG, Gibbs R and Paulk W. Intraoperative antibiotic irrigation as prophylaxis in abdominal hysterectomy: A preliminary report. South. Med. J. 77: 700, 198483

32. MT Cheng, MC Chang, ST Wang, WK Yu, CL Liu, TH Chen. Efficacy of Dilute Betadine Solution Irrigation in the Prevention of Postoperative Infection of Spinal Surgery Spine. 2005; 30(15): 1689-1693. C2005 Lippincott Williams \& Wilkins 